\title{
Predictors of Reoperation after Microdecompression in Lumbar Spinal Stenosis
}

\author{
Hee-Jong Hwang, Hyung-Ki Park, Gwang-Soo Lee, June-Young Heo, Jae-Chil Chang \\ Department of Neurosurgery, Soonchunhyang University College of Medicine, Seoul, Korea
}

\begin{abstract}
Objective: The risk factors of reoperation after microdecompression (MD) for lumbar spinal stenosis (LSS) are unclear. In this study, we presented the outcomes of MD for degenerative LSS and investigated the risk factors associated with reoperation. Methods: A retrospective review was conducted using the clinical records and radiographs of patients with LSS who underwent MD. For clinical evaluation, we used the Japanese Orthopedic Association (JOA) scoring system for low back pain, body mass index, and Charlson comorbidity index. For radiological evaluation, disc height, facet angle, and sagittal rotation angle were measured in operated segments. Also the Modic change and Pfirmann grade for degeneration in the endplate and disc were scored. Results: Forty-three patients aged $69 \pm 9$ years at index surgery were followed for $48 \pm 25$ months. The average preoperative JOA score was $6.9 \pm 1.6$ points. The score improved to $9.1 \pm 2.1$ points at the latest follow-up $(p<0.001)$. Seven patients $(16.3 \%)$ underwent reoperation. Clinical and radiological factors except operation level and Pfirrmann grade showed a $p$-value $>0.1$. Patients with Pfirmann grade IV and lower lumbar segment had a $29.1 \%$ rate of reoperation $(p=0.001)$, whereas patients without these factors had a $0 \%$ rate of reoperation.

Conclusion: Moderate disk degeneration (Pfirrmann IV) in lower lumbar segments is a risk factor of disk herniation or foraminal stenosis requiring reoperation after MD in LSS.
\end{abstract}

Key Words: Microdecompression $\cdot$ Lumbar spinal stenosis $\cdot$ Laminotomy $\cdot$ Outcome $\cdot$ Reoperation

\section{INTRODUCTION}

Lumbar spinal stenosis (LSS) is defined as reduction in surface area of the lumbar spinal canal and is a highly prevalent condition usually caused by a gradual, degenerative aging process $^{12,16}$. LSS can be associated with back pain and/or leg symptoms ${ }^{9)}$. The goal of conservative treatment is to reduce pain gradually over time; however, surgery is often recommended. The operative treatment for LSS and degenerative spondylolisthesis provides substantial lasting benefit compared with nonoperative care ${ }^{17,23,27}$. As a result, the number of surgical procedures performed for LSS has increased steadily as the oldest sector of the population continues to grow ${ }^{14,16}$. However, the optimal procedure remains controversial, and no obvious superiority of any specific technique has been identified $^{14,15)}$.

- Received: November 10, 2016 • Revised: December 22, 2016

- Accepted: December 26, 2016

Corresponding Author: Hyung-Ki Park

Department of Neurosurgery, Soonchunhyang University Seoul

Hospital, Soonchunhyang University College of Medicine, 59

Daesagwan-ro, Yongsan-gu, Seoul 04401, Korea

Tel: +82-2-709-9268, Fax: +82-2-792-5976

E-mail:schnsphk@gmail.com

@This is an open access article distributed under the terms of the Creative Commons Attribution Non-Commercial License (http://creativecommons.org/licenses/by-nc/4.0/) which permits unrestricted non-commercial use, distribution, and reproduction in any medium, provided the original work is properly cited.
A decompressive procedure is the basic method to alleviate the symptoms associated with neurological compression. However, decompression alone can result in the progression of instability, which usually requires reoperation ${ }^{22}$. Surgical fusion with decompression has been recommended for stabilizing the unstable lumbar vertebrae ${ }^{11,14,18)}$. However, this procedure can be associated with iatrogenic complications, a longer postoperative recovery before returning to activity, postsurgical complications, and greater costs compared to decompression alone ${ }^{3,7,14)}$.

Recently, various microdecompression (MD) methods have been used for the treatment of LSS. However, despite many advantages, the main concern regarding MD during the follow-up period is the risk of reoperation, which is higher than for fusion surgery. Due to the limited number of studies, the risk factors of reoperation after MD for LSS are unclear. Therefore, the appropriate surgical indications for MD to reduce the risk of reoperation remain to be determined in LSS. In this study, we presented the outcomes of $\mathrm{MD}$ for degenerative LSS and investigated the risk factors associated with reoperation.

\section{MATERIALS AND METHODS}

\section{Patients}

A retrospective review was conducted using the clinical records and radiographs of patients with LSS who underwent 
MD between July 2006 and December 2013 at the Soonchunhyang University Seoul Hospital. Fifty of 56 patients were followed up, and $7(14 \%)$ died due to malignant tumor, heart disease, or stroke, regardless of operation. Finally, 43 patients were included in this study. The diagnosis of LSS was based on clinical symptoms such as low back pain, leg pain, numbness during standing or walking, and intermittent claudication. In all patients, stenotic spinal lesions were confirmed by magnetic resonance imaging (MRI). Clinical indications for MD were leg pain and/or leg numbness inducing intermittent claudication ( $>6$ weeks) rather than back pain. Furthermore, this procedure was preferentially considered over fusion surgery in older patients and those with comorbidities, regardless of persistent back pain. Radiological indications for this surgical procedure were LSS without instability and foraminal stenosis excluding degenerative lumbar spondylolisthesis ( $\geq 3 \mathrm{~mm}$ on the lateral neutral radiograph) and degenerative lumbar scoliosis (Cobb angle, $\geq 25^{\circ}$ ). Patients with LSS accompanying disc herniation at the same level were excluded.

\section{Operative Technique}

MD was modified from the previously reported unilateral approach method for bilateral decompression (ULBD) ${ }^{28}$. Laminotomy was performed on the contralateral side of lateral recess stenosis in order to preserve as much of the facet joints as possible. If bilateral lateral recess stenosis was present, laminotomy was performed on both sides. Under a surgical microscope, the upper and lower lamina were partially removed in the area of the ligamentum flavum insertion. The basal part of the spinous process of the caudal half of the cranial lamina and a small cranial portion of the caudal lamina were removed with a high-speed drill. Next, the contralateral lamina was undercut with a high-speed air drill, leaving the ligamentum flavum in place as protection for the dural sac and the nerve root. Following sufficient resection of the bony segment, the ligamentum flavum was removed en bloc with a curette. After observing the inner aspect of the pedicle on the contralateral side, we confirmed adequate decompression of the contralateral side. Patients were generally allowed to walk with a corset brace within three days of surgery, and corset brace use was recommended for 4-6 weeks. Rehabilitation was not recommended.

\section{Clinical Evaluation}

For clinical evaluation, we used the Japanese Orthopedic Association (JOA) scoring system for low back pain. Preoperative clinical evaluation data and JOA scores were obtained from medical charts, and postoperative final scores were obtained by data collection and telephone interviews. Body mass index (BMI) and Charlson comorbidity index (CCI) were used to determine preoperative health of the surgical patients. Patients were questioned regarding current status; subjective im- provement in symptoms; satisfaction with the surgical procedure; and operative results, associated medical conditions, and current therapy. The modified grading system devised by Finneson and Cooper was used to assess the outcomes. Reoperation was defined as cases that underwent repeat operation in the same MD segment.

\section{Radiographic Evaluation}

Pre- and postoperative radiographs of the 43 patients were examined by one of the authors without knowledge of the clinical features of the patients. Evaluations were also performed independent of clinical assessment. Measurements to determine spondylolisthesis, facet angle, and sagittal rotation angle were performed in operated segments. Disc height was calculated as the mean of the anterior, middle, and posterior disc heights. We scored the Modic change and Pfirrmann grade for degeneration in the endplate and disc on preoperative MRI T2 spin-echo weighted images ${ }^{21,29)}$.

\section{Statistical Analysis}

SPSS ver. 12.0 (SPSS Inc., Chicago, IL, USA) was utilized for statistical analyses. Data are presented as mean \pm standard deviation. The paired t-test was used to analyze the significance of differences between the preoperative JOA score and at the latest postoperative follow-up. Patients were stratified into no reoperation versus reoperation groups. Clinical and radiological factors in the reoperation and no reoperation groups were compared using Fisher exact test for analyzing the risk factors of reoperation. First, p-values less than 0.05 were considered statistically significant. If there was no significance at the 0.05 level, the significance level of 0.1 was determined as borderline significant difference considering the small size of the reoperation group.

\section{RESULTS}

\section{Demographic Data}

Forty-three patients (17 males, 26 females) aged 50-82 years (69 \pm 9 years) at index surgery were followed for $48 \pm 25$ months (range, 19-95 months). Twenty-nine patients (67.4\%) underwent single-level surgery, and 14 patients (32.6\%) underwent multilevel surgery (13 two-level and 1 three-level). The levels of surgery were L1-L2 in one patient, L2-L3 in 6 patients, L3-L4 in 13 patients, L4-L5 in 33 patients, and L5-S1 in 5 patients (Table 1), resulting in high comorbidity. Thirty-seven patients (86\%) had multiple medical problems, including hypertension $(28,65.0 \%)$, diabetes mellitus $(17,39.5 \%)$, depression $(7,16.3 \%)$, heart disease $(6,13.9 \%)$, systemic cancer $(5$, $11.6 \%)$, kidney disease $(4,9.3 \%)$, cerebrovascular disease (2, $4.7 \%)$, and hypothyroidism $(1,2.3 \%)$. The median BMI and CCI were $24.9(20.2-30.3)$ and $5(2-10)$, respectively (Table 1$)$. 


\section{Radiological Data}

Preoperative facet angle ranged from $30.7^{\circ}$ to $71.3^{\circ}$, with a median of $51.8^{\circ}$. The sagittal rotational angle ranged from $0.3^{\circ}$ to $19.7^{\circ}$, with a median of $5.9^{\circ}$. Disc height ranged from 4.2 to $12.5 \mathrm{~mm}$, with a median of $7.2 \mathrm{~mm}$. Preoperative Modic classifications were normal at $37(63.8 \%)$, type I at $3(5.2 \%)$, type II at 12 (20.7\%), and type III at 6 disc levels (10.3\%). Preoperative Pfirrmann grade of intervertebral disc was III at 12 (20.7\%), IV at 32 (55.2\%), and V at 14 (24.1\%) disc levels (Table 2).

\section{Clinical Outcomes}

The average preoperative JOA score (total points, 15) for all patients was $6.9 \pm 1.6$ points. The score improved to $11.2 \pm$ 1.7 points at 1 year after surgery and then decreased to $9.1 \pm$ 2.1 points at the latest follow-up $(\mathrm{p}<0.001)$ (Table 3$)$. Six patients had excellent outcome (14.0\%), 13 patients had good outcome (30.2\%), 11 patients had fair outcome (25.6\%), 2 patients had marginal outcome (4.6\%), and 4 patients had poor

Table 1. Characteristics of study patients

\begin{tabular}{|c|c|}
\hline Variable & Value \\
\hline No. of patients & 43 \\
\hline Sex, male:female & $17: 26$ \\
\hline Age (yr), mean $\pm \mathrm{SD}$ (range) & $69 \pm 9(50-82)$ \\
\hline Follow-up period (mo), mean $\pm \mathrm{SD}$ (range) & $48 \pm 25(19-95)$ \\
\hline Comorbidity & $37(86.0)$ \\
\hline Hypertension & $28(65.1)$ \\
\hline Diabetes mellitus & $17(39.5)$ \\
\hline Depression & $7(16.3)$ \\
\hline Heart disease & $6(13.9)$ \\
\hline Systemic cancer & $5(11.6)$ \\
\hline Kidney disease & $4(9.3)$ \\
\hline Cerebrovascular accident & $2(4.7)$ \\
\hline Hypothyroidism & $1(2.3)$ \\
\hline Body mass index $\left(\mathrm{kg} / \mathrm{m}^{2}\right)$, median (range) & $24.9(20.2-30.3)$ \\
\hline Operation levels & 58 \\
\hline Single level/multiple level; & $29(67.4) / 14(32.6)$ \\
\hline $\mathrm{L} 1 / 2$ & $1(1.7)$ \\
\hline $\mathrm{L} 2 / 3$ & $6(10.3)$ \\
\hline $\mathrm{L} 3 / 4$ & $13(22.4)$ \\
\hline $\mathrm{L} 4 / 5$ & $33(56.9)$ \\
\hline $\mathrm{L} 5 / \mathrm{S} 1$ & $5(8.6)$ \\
\hline Charlson comorbidity index, median (range) & $5(2-10)$ \\
\hline
\end{tabular}

Values are presented as number (\%) unless otherwise indicated. $\mathrm{SD}$, standard deviation. outcome (9.3\%) on evaluation at the latest follow-up. Seven patients (16.3\%) underwent reoperation (Table 3).

\section{Reoperation}

During the follow-up period, 7 patients (16.3\%) underwent reoperation at the same level (Table 4). Two of the 7 patients underwent reoperation within 6 months of the index procedure. The causes of reoperation were disc herniation $(n=5)$, foraminal stenosis $(n=1)$, and listhesis $(n=1)$. Among the 7 reoperated patients, 3 patients underwent microdiscectomy without fusion, whereas fusion was performed at the same level in 4 patients (Fig. 1).

\section{Factors Related to Reoperation}

Using Fisher exact test and Mann-Whitney U-test, clinical and radiological factors except operation level and Pfirrmann

Table 2. Radiologica characteristics of study patients

\begin{tabular}{lc}
\hline \hline Variable & Value \\
\hline Facetangle & $51.8(30.7-71.3)$ \\
Sagittal rotation angle & $5.9(0.3-19.7)$ \\
Disc height (mm) & $7.2(4.2-12.5)$ \\
Modic change & \\
0 & $37(63.8)$ \\
I & $3(5.2)$ \\
II & $12(20.7)$ \\
III & $6(10.3)$
\end{tabular}

Pfirrmann grade

III $12(20.7)$

IV $\quad 32(55.2)$

$\mathrm{V}$

Values are presented as median (range) or number (\%).

Table 3. Clinical outcome of study patients

\begin{tabular}{lcc}
\hline Variable & Value & p-value \\
\hline JOA score & & \\
Preoperative & $6.9 \pm 1.6$ & \\
Postoperative 1 yr & $11.2 \pm 1.7$ & $<0.001$ \\
Final F/U ( $>3$ yr) & $9.1 \pm 2.1$ & \\
Outcomes by Finneson \& Cooper & & \\
Excellent & $6(14.0)$ & \\
Good & $13(30.2)$ & \\
Fair & $11(25.6)$ & \\
Marginal & $2(4.6)$ \\
Poor & $4(9.3)$ \\
Reoperation & $7(16.3)$ & \\
\hline
\end{tabular}

Values are presented as mean \pm standard deviation or number (\%).

JOA, Japanese Orthopedic Association; F/U, follow-up. 
grade showed a p-value $>0.1$ (operation level and Pfirrmann grade showed p-values of 0.083 and 0.051 , respectively) (Table 5). Lower lumbar segment was associated with a $18.4 \%$ rate of reoperation $(\mathrm{p}=0.08)$. Pfirrmann grade IV was associated with a $21.9 \%$ rate of reoperation $(\mathrm{p}=0.01)$. Patients with Pfirrmann grade IV and lower lumbar segment had a $29.1 \%$ rate of reoperation $(p=0.001)$, but none of the patients without these factors had reoperation (Fig. 2).

\section{DISCUSSION}

Although incidence and prevalence of LSS are not fully established, common symptoms include impaired walking and disability in older people ${ }^{10,16}$. LSS is the most common reason for spinal surgery in older patients ${ }^{5}$; however, the management of LSS remains controversial ${ }^{5}$. There is growing evidence that surgical decompression offers an advantage over nonsur-

Table 4. Characteristics of 7 patients requiring reoperation

\begin{tabular}{cccccll}
\hline \hline No. & Sex/age & Interval (mo) & Level & Modic/ Pfirmann G & \multicolumn{1}{c}{ Cause } & Name of operation \\
\hline 1 & $\mathrm{M} / 68$ & 36 & $\mathrm{~L} 4 / 5$ & $\mathrm{~N} / 4$ & Foraminal stenosis & Fusion \\
2 & $\mathrm{M} / 57$ & 25 & $\mathrm{~L} 4 / 5$ & $\mathrm{~N} / 4$ & Listhesis & Fusion \\
3 & $\mathrm{M} / 50$ & 23 & $\mathrm{~L} 4 / 5$ & $\mathrm{~N} / 4$ & Disc herniation & Fusion \\
4 & $\mathrm{M} / 71$ & 16 & $\mathrm{~L} 4 / 5$ & $\mathrm{~N} / 4$ & Disc herniation & Fusion \\
5 & $\mathrm{~F} / 53$ & 3 & $\mathrm{~L} 5 / \mathrm{S} 1$ & $\mathrm{~N} / 4$ & Foraminal disc & Microdiscectomy \\
6 & $\mathrm{~F} / 63$ & 4 & $\mathrm{~L} 4 / 5$ & $\mathrm{~N} / 4$ & Disc herniation & Microdiscectomy \\
7 & $\mathrm{~F} / 79$ & 12 & $\mathrm{~L} 4 / 5$ & $\mathrm{II} / 4$ & Disc herniation & Microdiscectomy \\
\hline
\end{tabular}

Table 5. Factors associated with reoperation in the study group

\begin{tabular}{|c|c|c|c|}
\hline Variable & No reoperation group & Reoperation group & $\mathrm{p}$-value \\
\hline Age (yr) & $71(64-75)$ & $68(57-77)$ & $0.451^{+}$ \\
\hline Sex & & & $0.409^{*}$ \\
\hline Male & $18(35)$ & $4(57)$ & \\
\hline Female & $33(65)$ & $3(43)$ & \\
\hline Body mass index $\left(\mathrm{kg} / \mathrm{m}^{2}\right)$ & $25.0(23.2-26.5)$ & $21.7(20.9-30.2)$ & $0.177^{+}$ \\
\hline Charlson comorbidity index & $5(4-6)$ & $5(4-7)$ & $0.987^{+}$ \\
\hline Operation level & & & $0.083^{*}$ \\
\hline Upper level (L1/2, 2/3, 3/4) & $20(39)$ & $0(0)$ & \\
\hline Lower level (L4/5, L5/S1) & $31(61)$ & $7(100)$ & \\
\hline Motion & $1.44(1-2.12)$ & $1.32(0.92-2.78)$ & $0.616^{+}$ \\
\hline Facet angle & $52.1(47.6-55.5)$ & $48.4(42.4-53.6)$ & $0.130^{+}$ \\
\hline Sagittal rotation angle & $6.5(4.1-10.2)$ & $5.4(3.3-7.1)$ & $0.257^{+}$ \\
\hline Disc height & $9.72(7.7-11.4)$ & $9.4(7.7-11.7)$ & $0.896^{+}$ \\
\hline Modic change & & & $0.80^{*}$ \\
\hline 0 & $31(61)$ & $6(86)$ & \\
\hline I & $3(6)$ & $0(0)$ & \\
\hline II & $11(22)$ & $1(14)$ & \\
\hline III & $6(12)$ & $0(0)$ & \\
\hline Pfirrmann grade & & & $0.051^{*}$ \\
\hline III & $12(24)$ & $0(0)$ & \\
\hline IV & $25(49)$ & $7(100)$ & \\
\hline $\mathrm{V}$ & $14(27)$ & $0(0)$ & \\
\hline Spondylolisthesis & & & $0.343^{*}$ \\
\hline Yes & $40(78)$ & $4(57)$ & \\
\hline No & $11(22)$ & $3(43)$ & \\
\hline
\end{tabular}

Values are presented as median (interquartile range) or number (\%).

"p-value based on Fisher exact test. ${ }^{+}$p-value based on Mann-Whitney U-test. 

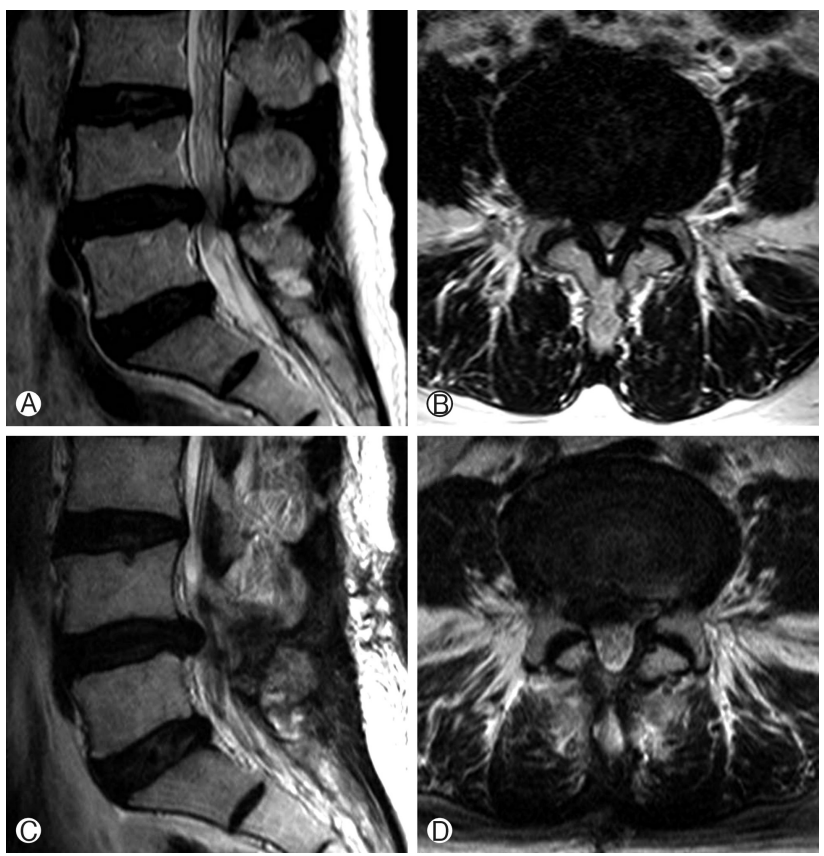

Fig. 1. Case 3. Preoperative sagittal (A) and axial (B) magnetic resonance $(\mathrm{MR})$ images showing stenosis and disc herniation in L4/5 sagittal (C) and axial (D) MR images at 23 months after surgery. The patient experienced low back pain and right leg pain and underwent fusion surgery.

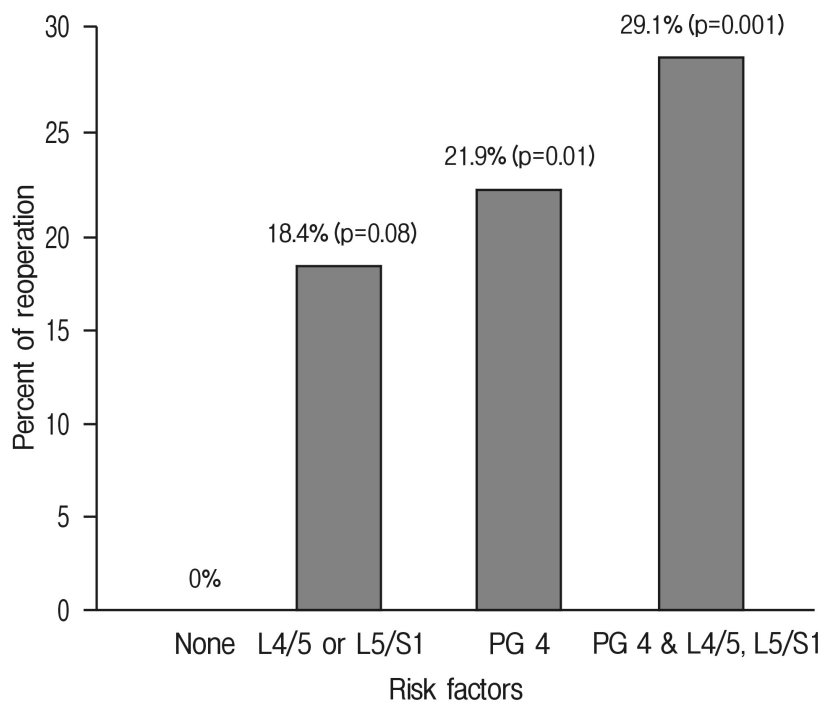

Fig. 2. Bar graph showing the percentage and significance of patients with Pfirrmann grade IV or lower lumbar segments requiring a reoperation; 29.1\% of patients with Pfirrmann grade IV and lower lumbar segments underwent a reoperation $(\mathrm{p}=0.001)$.

gical treatments for selected patients with persistent severe symptoms. Kovacs et al. ${ }^{12)}$ suggested that surgery is superior to conservative treatment in patients with symptomatic LSS when conservative treatment for three to 6 months fails, based on a systematic review of randomized controlled trials.
However, when surgery is suggested, the type of surgery that should be performed also remains controversial ${ }^{5,9)}$. Machado et al. ${ }^{14)}$ investigated the effectiveness of surgery for LSS via a meta-analysis and suggested that the relative efficacy of various surgical options for treating LSS remains uncertain, showing that decompression with fusion is not more effective than decompression alone. Therefore, surgeons should choose the surgical technique based on their own experience; the risk of complications; and the patient's socioeconomic situation, comorbidities, and preference. The decision is also influenced by the surgeon's beliefs regarding the role of surgery in spinal disorders and the surgical instrumentation and skills available. However, there is significant heterogeneity within the patient population, which might have an impact on treatment response $^{22)}$, indicating that the selection of appropriate patients is very important for improving the results of surgical treatment.

LSS is usually treated surgically with fusion and/or decompression. Generally, decompression of nerve root(s) is essential for relieving neurological symptoms, and fusion can be considered for relieving low back pain due to severe disc degeneration, deformity, or spinal instability. Decompression has been the historical and basic procedure to relieve patient symptoms related with neurological compression ${ }^{6}$. Recently, various minimally invasive spinal surgery techniques have been developed for preventing postoperative instability with the aim of improving clinical outcomes ${ }^{1,3,16,19)}$. Common characteristics of these techniques are smaller incisions, preservation of stabilizing ligamentous and bony spinal structures, and preservation of posterior motion segments and paraspinalmuscles $^{3,16)}$. The reported advantages included reduction of operative blood loss, faster recovery, shortening of hospital stay, and reduced need for analgesics, $3,15,16,18$ ).

The author's operative technique is $\mathrm{MD}$ via unilateral or bilateral laminotomy, which has the same above-mentioned features. However, despite the many advantages, possible disadvantages of MD have been reported, such as higher complication rates due to the difficulty of manipulating instruments through a small space (dural sac retraction and dural tear), inadequate decompression, and increased operation time due to the steep learning curve ${ }^{15)}$. Although these disadvantages can be overcome with time and effort, postoperative ongoing instability of the operation segment is a disadvantage that cannot be overlooked. We hypothesize that, in patients with an underlying biomechanically stable spine, decompression alone using a less invasive technique can be sufficient. The definition of instability as a loss of motion segment stiffness has also been supported by Panjabi et al. ${ }^{20)}$. However, the definition of instability remains controversial ${ }^{5)}$.

Alimi et al. ${ }^{1)}$ reported a reoperation rate of $3.5 \%$ requiring fusion at the same level in a study on minimally invasive laminectomy of LSS with a mean follow-up of 28.8 months. Blumenthal et al. ${ }^{4)}$ studied radiographic predictors of delayed instability following decompression without fusion for degenerative Grade I lumbar spondylolisthesis. Reoperation was performed in 15 of 40 patients (37.5\%) for pain caused by insta- 
bility at the index level, with a mean follow-up duration of 3.6 years. They claimed that patients with motion at spondylolisthesis $>1.25 \mathrm{~mm}$, disc height $>6.5 \mathrm{~mm}$, and facet angle $>50^{\circ}$ were more likely to experience instability. Takenaka et $\mathrm{al}^{24)}$ investigated factors related to the development of post decompression lumbar disc herniation after bilateral partial laminectomy in LSS. They revealed that preoperative retrolisthesis was the sole significant risk factor. In our study, 7 of 43 patients (16.3\%) underwent reoperation at the operated segment during the mean follow-up of 2 years. The causes of reoperation were disc herniation in 5 patients, foraminal stenosis in 1 , and listhesis in 1 . Three patients underwent microdiscectomy without fusion, whereas fusion was performed at the same level in 4 patients. This 4 patients needed fusion surgery because of diagnosis that belonged to the indications of fusion (Fig. 1). That was spinal instability due to listhesis and foraminal stenosis, severe decreasing of disc height. Among the 7 reoperated patients, there was no radiological evidence of vertebral hypermobility or a significant increase in spondylolisthesis. All patients underwent MD for LSS accompanying the characteristic Pfirmann grade IV disc degeneration in lower lumbar segments (L4/5, L5/S1). Notably, LSS patients with Pfirrmann grade IV in lower lumbar segments had a higher possibility to undergo reoperation at the same level after MD.

The degenerative processes of the lumbar spine are generally initiated from the intervertebral disk and facet joints and can occur continuously or independently of the disk and undergo degenerative change characterized by cartilage thinning, sclerotic changes in the subchondral bone, osteophyte formation, synovial inflammation, and capsular ligament laxity ${ }^{8,13)}$. The macroscopic appearance of lumbar disk degeneration has been classified into stages defined by Thompson et al. ${ }^{25}$. The stages are described in general terms: I, normal juvenile disk; II, normal adult disk; III, mild disk degeneration; IV, moderate disk degeneration; and V, severe disk degeneration ${ }^{2}$. Pfirrmann et $\mathrm{al}^{21,26}$ devised a grading system for disc degeneration based on MRI signal intensity, disc structure, distinction between nucleus and anulus, and disc height. Degenerative processes in the disk and facet joints affect the stability of the motion segment ${ }^{13)}$. The degenerative process of the spine is usually divided into 3 phases, inflammation, instability, and restabilization $^{13,18)}$. Subsequently, Pfirrmann grade IV can be considered the most unstable state of the degenerative process before stabilization. Additionally, greater mobility and pressure exist in the area with like lower cervical or lower lumbar spine ${ }^{13)}$. Eventually, unstable disc degeneration in the lower lumbar segment continues with instability after MD. This condition can trigger restenosis or disc herniation in the same segment.

The main limitations were the small sample size and the medical comorbidities present in $86 \%$ of patients, which indicates that the data might not be representative of the majority of patients with LSS. Second, this was a case-control study with retrospective data collection. Third, the data were collected exclusively by and for our own hospital, which could have led to "site-specific bias". Fourth, the sample size of the control group was small (less than 10), which might have been due to the small number of patients in the reoperation group. However, increasing the sample size of the reoperation group was beyond our control. The p-values for between-group comparisons in the range of $0.06-0.10$ should be considered as potential evidence of underpowered evaluations. Our study results should be validated by a randomized control trial with a larger sample size.

\section{CONCLUSION}

The present study revealed that moderate disk degeneration (Pfirrmann IV) in lower lumbar segments is a risk factor of disk herniation or foraminal stenosis requiring reoperation after MD in LSS. This finding should be considered when selecting the proper patients for MD in LSS.

\section{CONFLICT OF INTEREST}

No potential conflict of interest relevant to this article was reported.

\section{REFERENCES}

1. Alimi M, Hofstetter CP, Pyo SY, Paulo D, Härtl R: Minimally invasive laminectomy for lumbar spinal stenosis in patients with and without preoperative spondylolisthesis: clinical outcome and reoperation rates. J Neurosurg Spine 22:339-352, 2015

2. Ball JR, Hurlbert RJ: Concepts of Disk Degeneration and Regeneration in Winn R, Winn HR(eds): Youmans Neurological Surgery, ed 6. Philadelphia: Saunders, pp2752-2762, 2011

3. Banczerowski P, Czigléczki G, Papp Z, Veres R, Rappaport HZ, Vajda J: Minimally invasive spine surgery: systematic review. Neurosurg Rev 38:11-26, 2015

4. Blumenthal C, Curran J, Benzel EC, Potter R, Magge SN, Harrington JF Jr, et al: Radiographic predictors of delayed instability following decompression without fusion for degenerative grade I lumbar spondylolisthesis. J Neurosurg Spine 18:340346, 2013

5. Burgstaller JM, Porchet F, Steurer J, Wertli MM: Arguments for the choice of surgical treatments in patients with lumbar spinal stenosis - a systematic appraisal of randomized controlled trials. BMC Musculoskelet Disord 16:96, 2015

6. Caputy AJ, Luessenhop AJ: Long-term evaluation of decompressive surgery for degenerative lumbar stenosis. J Neurosurg 77: 669-676, 1992

7. Deyo RA, Martin BI, Ching A, Tosteson AN, Jarvik JG, Kreuter $\mathrm{W}$, et al: Interspinous spacers compared with decompression or fusion for lumbar stenosis: complications and repeat operations in the Medicare population. Spine (Phila Pa 1976) 38:865-872, 2013

8. Fujiwara A, Lim TH, An HS, Tanaka N, Jeon CH, Andersson $\mathrm{GB}$, et al: The effect of disc degeneration and facet joint osteoarthritis on the segmental flexibility of the lumbar spine. Spine (Phila Pa 1976) 25:3036-3044, 2000

9. Gibson JN, Waddell G: Surgery for degenerative lumbar spon- 
dylosis. Cochrane Database Syst Rev (4):CD001352, 2005

10. Goh KJ, Khalifa W, Anslow P, Cadoux-Hudson T, Donaghy M: The clinical syndrome associated with lumbar spinal stenosis. Eur Neurol 52:242-249, 2004

11. Johnsson KE, Redlund-Johnell I, Udén A, Willner S: Preoperative and postoperative instability in lumbar spinal stenosis. Spine (Phila Pa 1976) 14:591-593, 1989

12. Kovacs FM, Urrútia G, Alarcón JD: Surgery versus conservative treatment for symptomatic lumbar spinal stenosis: a systematic review of randomized controlled trials. Spine (Phila Pa 1976) 36:E1335-1351, 2011

13. Leone A, Guglielmi G, Cassar-Pullicino VN, Bonomo L: Lumbar intervertebral instability: a review. Radiology 245:62-77, 2007

14. Machado GC, Ferreira PH, Harris IA, Pinheiro MB, Koes BW, van Tulder M, et al: Effectiveness of surgery for lumbar spinal stenosis: a systematic review and meta-analysis. PLoS One 10: e0122800, 2015

15. Mobbs RJ, Li J, Sivabalan P, Raley D, Rao PJ: Outcomes after decompressive laminectomy for lumbar spinal stenosis: comparison between minimally invasive unilateral laminectomy for bilateral decompression and open laminectomy: clinical article. J Neurosurg Spine 21:179-186, 2014

16. Nerland US, Jakola AS, Solheim O, Weber C, Rao V, Lonne G, et al: Minimally invasive decompression versus open laminectomy for central stenosis of the lumbar spine: pragmatic comparative effectiveness study. BMJ 350:h1603, 2015

17. Ng LC, Tafazal S, Sell P: The effect of duration of symptoms on standard outcome measures in the surgical treatment of spinal stenosis. Eur Spine J 16:199-206, 2007

18. Omidi-Kashani F, Hasankhani EG, Ashjazadeh A: Lumbar spinal stenosis: who should be fused? An updated review. Asian Spine J 8:521-530, 2014

19. Overdevest GM, Jacobs W, Vleggeert-Lankamp C, Thomé C, Gunzburg R, Peul W: Effectiveness of posterior decompression techniques compared with conventional laminectomy for lumbar stenosis. Cochrane Database Syst Rev (3):CD010036, 2015

20. Panjabi MM, Krag MH, White AA 3rd, Southwick WO: Effects of preload on load displacement curves of the lumbar spine.
Orthop Clin North Am 8:181-192, 1977

21. Pfirrmann CW, Metzdorf A, Zanetti M, Hodler J, Boos N: Magnetic resonance classification of lumbar intervertebral disc degeneration. Spine (Phila Pa 1976) 26:1873-1878, 2001

22. Resnick DK, Watters WC 3rd, Sharan A, Mummaneni PV, Dailey AT, Wang JC, et al: Guideline update for the performance of fusion procedures for degenerative disease of the lumbar spine. Part 9: lumbar fusion for stenosis with spondylolisthesis. J Neurosurg Spine 21:54-61, 2014

23. Rihn JA, Hilibrand AS, Zhao W, Lurie JD, Vaccaro AR, Albert TJ, et al: Effectiveness of surgery for lumbar stenosis and degenerative spondylolisthesis in the octogenarian population: analysis of the Spine Patient Outcomes Research Trial (SPORT) data. J Bone Joint Surg Am 97:177-185, 2015

24. Takenaka S, Tateishi K, Hosono N, Mukai Y, Fuji T: Preoperative retrolisthesis as a risk factor of postdecompression lumbar disc herniation. J Neurosurg Spine 24:592-601, 2016

25. Thompson JP, Pearce RH, Schechter MT, Adams ME, Tsang IK, Bishop PB: Preliminary evaluation of a scheme for grading the gross morphology of the human intervertebral disc. Spine (Phila Pa 1976) 15:411-415, 1990

26. Urrutia J, Besa P, Campos M, Cikutovic P, Cabezon M, Molina $M$, et al: The Pfirrmann classification of lumbar intervertebral disc degeneration: an independent inter- and intra-observer agreement assessment. Eur Spine J 25:2728-2733, 2016

27. Weinstein JN, Lurie JD, Tosteson TD, Zhao W, Blood EA, Tosteson AN, et al: Surgical compared with nonoperative treatment for lumbar degenerative spondylolisthesis. four-year results in the Spine Patient Outcomes Research Trial (SPORT) randomized and observational cohorts. J Bone Joint Surg Am 91: 1295-1304, 2009

28. Yang SM, Park HK, Chang JC, Kim RS, Park SQ, Cho SJ: Minimum 3-year outcomes in patients with lumbar spinal stenosis after bilateral microdecompression by unilateral or bilateral laminotomy. J Korean Neurosurg Soc 54:194-200, 2013

29. Zhang YH, Zhao CQ, Jiang LS, Chen XD, Dai LY: Modic changes: a systematic review of the literature. Eur Spine J 17:12891299, 2008 